\title{
Efektivitas Komunikasi Pemasaran Melalui Media Sosial untuk Menumbuhkan Kesadaran Merek Ladang Lima
}

\author{
Dinda Satya Rani ${ }^{1}$, Sri Tjondro Winarno ${ }^{2}$, Eko Priyanto ${ }^{3}$ \\ IAgribisnis, Universitas Pembangunan Nasional “Veteran” Jawa Timur, Jl. Raya Rungkut Madya, Surabaya, 60294 \\ E-mail: dindasatya20@gmail.com.id \\ ${ }^{2}$ Agribisnis, Universitas Pembangunan Nasional “Veteran” Jawa Timur, Jl. Raya Rungkut Madya, Surabaya, 60294 \\ E-mail: sritjondro_w@upnjatim.ac.id \\ ${ }^{3}$ Agribisnis, Universitas Pembangunan Nasional “Veteran” Jawa Timur, Jl. Raya Rungkut Madya, Surabaya, 60294 \\ E-mail: priyantoeko03@gmail.com
}

\begin{abstract}
The purpose of this study is to analyze the marketing communications that have been carried out by PT ABA through social media to raise awareness of the Ladang Lima brand. The object of this research is Ladang Lima Instagram, with the sample being Ladang Lima Instagram followers. The research method used is descryptive quantitative with the Customer Response Index (CRI). The result of this research is the marketing communication carried out by the company through social media Instagram has been effective in growing brand awareness, with a CRI value of 43.25\%, this is also supported through analysis of brand awareness at the top of the mind level, the first healthy food brand mentioned by the respondent with the most answers was Ladang Lima. PT ABA lost the most consumer responses in the intention to action stage on the CRI hierarchy of 20.67\%, meaning that after seeing marketing communications through Ladang Lima's Instagram, many respondents had the intention to buy Ladang Lima products, but did not actually take the purchase action.
\end{abstract}

Keywords_-: Effectiveness;Marketing;Communication;Awareness.

\section{PENDAHULUAN}

Perusahaan jika ingin memenangi persaingan dalam suatu pasar serta selalu menginginkan agar dapat mempertahankan posisinya terutama ditengah derasnya arus perdagangan bebas, harus mempunyai strategi pemasaran yang tepat dan akurat. Pemasaran berperan penting karena keberhasilan perusahaan mempertahankan atau meningkatkan posisi salah satunya ditentukan oleh berhasil tidaknya diimplementasikan kegiatan pemasaran secara profesional dalam suatu perusahaan.

Merek selain mencerminkan keaslian, nilai, dan komitmen terhadap barang dan jasa yang diperkenalkan kepada konsumen, juga memiliki fungsi mengurangi risiko terkait barang dan jasa bagi konsumen serta membangun ikatan sosial tanpa perlu mengungkapkan identitas perusahaan. Membangun identitas berbanding lurus dengan komunikasi antara merek dan konsumen, semakin besar kekuatan komunikasi antara merek dan konsumen, maka akan semakin tinggi juga preferensi merek dan loyalitas merek konsumen (BİLGİN, 2018).

Kegiatan komunikasi yang dilakukan secara tepat dan konsisten, dapat menumbuhkan kesadaran merek di benak konsumen. Kesadaran merek (brand awareness) adalah kesanggupan konsumen untuk mengenali atau mengingat kembali merek dari suatu produk atau jasa yang dihasilkan oleh perusahaan (Nastain, 2017). Produk yang memiliki brand awareness lebih tinggi, akan tumbuh lebih baik di pasar dan membantu perusahaan dalam memperoleh keuntungan (Shahid et al., 2017). Menumbuhkan kesadaran merek tidaklah mudah dan instan, semakin banyaknya penawaran produk di pasar membuat perusahaan harus menghadapi tantangan untuk membedakan penawaran melalui pemasaran dan komunikasi, yang didalamnya harus mentransmisikan nilai-nilai emosional atau rasional yang dapat mempengaruhi perilaku pembelian konsumen (Mihaela, 2015). Menurut Tarigan \& Tritama (2016), komunikasi pemasaran adalah sarana bagi perusahaan untuk menginformasikan, membujuk, dan mengingatkan konsumen secara langsung maupun tidak langsung tentang produk dan merek yang telah dihasilkan oleh perusahaan. Komunikasi pemasaran diharapkan mampu menggerakkan sikap konsumen dan menghasilkan tiga tahap perubahan, yaitu perubahan pengetahuan (kognitif), perubahan sikap (afektif) dan perubahan tindakan (konatif) agar efektivitas komunikasi dapat tercapai, dalam hal ini, terdapat teori hierarchy of effects yang juga menjabarkan bahwa efektivitas didapatkan berdasarkan tahap demi tahap respon konsumen mulai dari kognitif, afektif, dan konatif. Efektivitas komunikasi pemasaran dapat diukur menggunakan metode CRI (Customer Response Index), yang terdiri dari lima tahap respon konsumen yaitu awareness (kesadaran), comprehend (pemahaman), interest (ketertarikan), intentions (niat), dan action (tindakan). Menurut Best (2009), upaya komunikasi pemasaran yang efektif dimulai dengan membangun kesadaran dan pemahaman tentang pesan di antara pelanggan sasaran, upaya yang telah berhasil kemudian akan menciptakan niat untuk membeli di antara sejumlah besar pelanggan sasaran, selanjutnya sebagian dari pelanggan bersedia melakukan pembelian.

Media yang sedang populer dikalangan masyarakat saat ini untuk melakukan komunikasi maupun interaksi dengan sesamanya adalah media sosial. Pengguna media sosial aktif di Indonesia hingga Januari 2020 adalah sebanyak 160 juta jiwa atau sebesar 59\% dari jumlah penduduk Indonesia (We Are Social \& Hootsuite, 2020). Pengguna media sosial yang cukup 
Website : http://agritek.unmermadiun.ac.id/index.php/agritek

besar merupakan peluang bagi perusahaan untuk mengembangkan aktivitas komunikasi pemasaran. Pemasaran melalui media sosial saat ini merupakan saluran pemasaran yang terluas, tercepat, termurah dan paling efektif dimana konsumen dapat memperoleh informasi dan fitur barang menarik dengan mudah (Iblasi et al., 2016).

PT ABA adalah produsen makanan sehat yang mengolah singkong menjadi tepung singkong dan berbagai produk turunan lain seperti mie sayur, cookies, pasta, maupun tepung bumbu. Produk-produk yang dihasilkan oleh PT ABA diberi merek bernama Ladang Lima. Komunikasi pemasaran yang dilakukan perusahaan adalah melalui media sosial, salah satunya yaitu Instagram, meskipun perusahaan telah melakukan komunikasi pemasaran, masalah utama di bidang pemasaran tetap terletak pada memperkenalkan produk serta menumbuhkan kesadaran merek di benak konsumen, hingga berdampak pada volume penjualan yang berfluktuasi. Perusahaan harus melakukan komunikasi pemasaran melalui media sosial yang lebih efektif untuk menumbuhkan kesadaran merek dibenak konsumen.

Tujuan dari penelitian ini adalah untuk menganalisis efektivitas komunikasi pemasaran yang telah dilakukan oleh PT ABA melalui media sosial untuk menumbuhkan kesadaran merek Ladang Lima.

\section{METODE PENELITIAN}

Penelitian dilakukan di PT ABA, produsen makanan sehat berbahan dasar singkong yang berlokasi di Surabaya dengan objek penelitian adalah media sosial Instagram Ladang Lima. Populasi dalam penelitian ini adalah pengikut (followers) media sosial Ladang Lima yang terdapat di Instagram yaitu sebanyak 98.400, pengambilan sampel dilakukan dengan teknik quota sampling, yaitu pengambilan sampel berdasarkan karakteristik dan jumlah yang ditentukan oleh peneliti sampai memenuhi kuota tertentu, dalam hal ini diambil 100 sampel pengikut Instagram Ladang Lima. Pemilihan elemen sampel pada quota sampling didasarkan pada kemudahan atau pertimbangan, yang berarti bahwa komposisi sampel akhir sangat mirip dengan komposisi populasi sasaran sehubungan dengan karakteristik yang telah ditentukan sebelumnya (Sarstedt et al., 2017). Karakteristik penentuan sampel pada penelitian ini, antara lain merupakan pengikut pada Instagram Ladang Lima serta merupakan pengguna asli dan aktif Instagram.

Data yang digunakan pada penelitian ini adalah data primer dan sekunder yang kemudian dinalisis secara deskriptif kuantitatif menggunakan metode CRI (Customer Response Index) untuk mengukur efektivitas komunikasi pemasaran yang telah dilakukan PT ABA melalui media sosial. CRI memiliki luaran berupa presentase mulai dari respon awareness (kesadaran) hingga action (tindakan), yang selanjutnya hasil presentase dari tiap respon dimasukkan ke dalam bagan hirarki CRI pada Gambar 1.

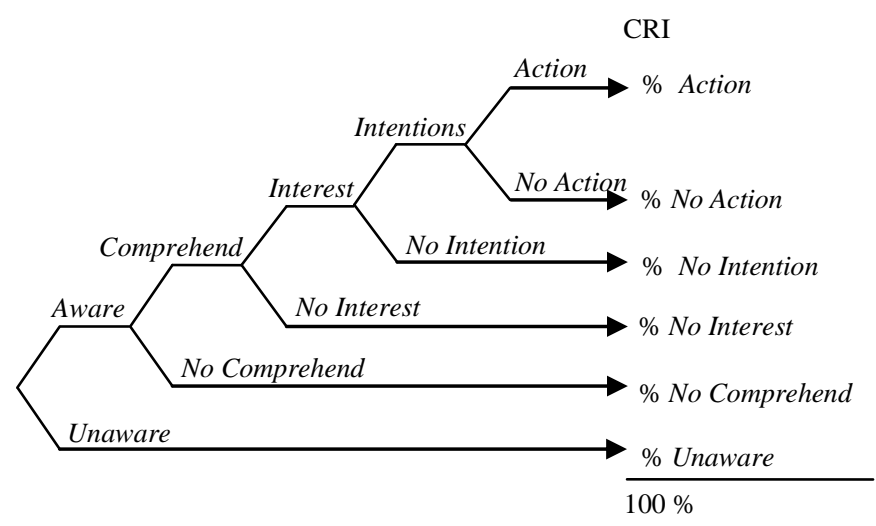

Gambar 1. Bagan Hirarki CRI

Sumber: Durianto (2003)

Hirarki Customer Response Index memiliki beberapa respon konsumen, kelima respon tersebut saling berhubungan dan membentuk sebuah tingkatan, sehingga dapat dikatakan bahwa audiens dalam merespon suatu iklan adalah dengan melewati tingkat demi tingkat yang dimulai dari awareness (kesadaran) sebagai respon tingkat dasar (Ernestivita, 2016). Customer Response Index menghasilkan persentase komunikasi pemasaran dari berbagai tingkat respon, setelah mendapatkan presentase aware sampai action dan unaware sampai no action, dilakukan perhitungan menggunakan meode CRI untuk mendapatkan nilai akhir Customer Response Index (Mutiara \& Hanifa, 2018). Rumus untuk memasukkan presentase atau data yang telah didapat ke dalam bagan hirarki Customer Response Index, yaitu (Durianto, 2003):

\footnotetext{
1. Unaware

2. No Comperhend=Awareness $x$ No Comprehend

3. No Interest $=$ Awareness $x$ Comprehend $x$ No Interest

4. No Intentions $=$ Awareness $x$ Comprehend $x$ Interest $x$ No Intentions

5. No Action $=$ Awareness $x$ Comprehend $x$ Interest $x$ Intentions $x$ No Action

6. Action $=$ Awareness $x$ Comprehend $x$ Interest $x$ Intentions $x$ Action
} 
Website : http://agritek.unmermadiun.ac.id/index.php/agritek

Rumus pada tahap action merupakan nilai dari Customer Response Index secara keseluruhan atau bisa disebut sebagai presentase terakhir yang memperlihatkan berapa persen responden yang telah melalui tahapan awareness hingga action, sehingga menggambarkan keefektivan komunikasi pemasaran. Keefektivitasan komunikasi pemasaran berdasarkan metode Customer Response Index (CRI) diukur dengan membandingkan nilai akhir CRI dengan nilai CRI pada tahap unaware, no comprehend, no interest, no intention, dan no action. Jika nilai persentase akhir CRI lebih besar dari nilai CRI unaware, no comprehend, no interest, no intention, dan no action, maka komunikasi pemasaran tersebut dapat dikatakan efektif, sebaliknya jika nilai persentase akhir CRI lebih kecil dari salah satu maupun keseluruhan nilai CRI yang unaware, no comprehend, no interest, no intention, dan no action maka komunikasi tersebut tidak efektif (Durianto, 2003).

\section{III.HASIL DAN PEMBAHASAN}

Data pada penelitian ini didapatkan melalui instrumen penelitian yaitu kuesioner, baik atau tidaknya instrumen penelitian ditentukan oleh validitas dan reliabilitasnya. Validitas menjelaskan sejauh mana ketepatan suatu pengukuran dalam mengukur sesuatu yang akan diukur (Yusup, 2018). Reliabilitas menunjukkan konsistensi dalam mengukur fenomena tertentu, artinya bisa mendapatkan hasil yang sama untuk pengukuran berulang dari fenomena yang sama (Ursachi et al., 2015). Hasil uji validitas pada kuesinoer penelitian ini dinyatakan valid karena $r$ hitung $>r$ tabel, dimana $r$ tabel dengan $n=100$ dan $\alpha=0,05$ bernilai 0,198. Uji reliabilitas dinyatakan reliabel karena Cronbach's Alpha bernilai 0,754 lebih besar dari 0,70. Instrumen dikatakan reliabel dan memliki tingkat konsistensi yang dapat diterima jika Cronbach's Alpha mencapai 0,70 (Nawi et al., 2020).

Penelitian ini menggunakan responden berupa pengikut Instagram Ladang Lima. Karakteristik responden pada penelitian ini berdasarkan jenis kelamin adalah $91 \%$ perempuan dan 9\% laki-laki, dengan usia didominasi oleh rentang 26 - 35 tahun sebanyak 53\%, usia $17-25$ tahun sebanyak 31\%, dan usia lebih dari 36 tahun sebanyak 16\%. Pekerjaan responden paling banyak sebagai ibu rumah tangga $32 \%$, pegawai swasta $25 \%$, pelajar atau mahasiswa $25 \%$, sisanya bekerja dari berbagai bidang, sedangkan pendapatan perbulan didominasi pada rentang $\mathrm{Rp} 3.100 .000$ - Rp 6.000.000. Domisili responden paling banyak terletak di Surabaya, Sidoarjo, dan Malang. Lama responden membuka Instagram dalam satu hari didominasi waktu $1-2$ jam.

Data yang telah terkumpul dianalisis menggunakan perhitungan Customer Response Index untuk mendapatkan nilai efektivitas komunikasi pemasaran melalui media sosial yang telah dilakukan perusahaan, berikut hasil pengolahan data dipaparkan pada gambar 2 .

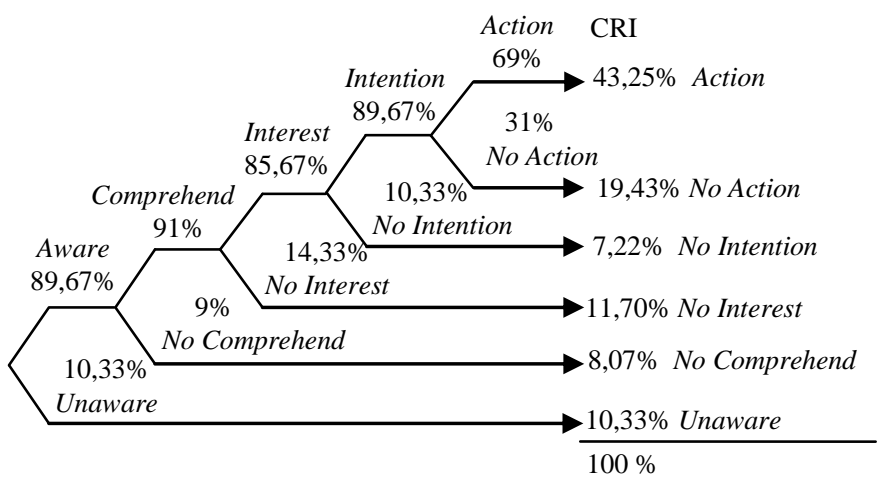

Gambar 2. Hirarki CRI Komunikasi Pemasaran Ladang Lima

Komunikasi pemasaran yang dilakukan PT ABA untuk menumbuhkan kesadaran merek salah satunya dilakukan melalui media sosial Instagram. Komunikasi pemasaran atau periklanan yang efektif adalah komunikasi yang mampu menjadikan masyarakat sebagai konsumen melalui beberapa tahapan respon, mulai dari kesadaran hingga tindakan nyata pembelian (Andry et al., 2019). Metode Customer Response Index dimulai dari awareness (kesadaran) pada tahap awal, diketahui pada gambar 2, sebanyak 89,67\% responden aware atau sadar, mengenal, dan meningat merek Ladang Lima, sedangkan 10,33\% responden menyatakan unaware atau tidak sadar akan merek Ladang Lima. Tahapan selanjutnya yaitu comprehend (pemahaman), dari responden yang aware terhadap merek Ladang Lima, sebanyak 91\% menyatakan comprehend atau memahami komunikasi pemasaran yang telah dilakukan perusahaan melalui Instagram Ladang Lima, sedangkan 9\% menyatakan tidak memahami dengan alasan kurang membaca informasi mengenai produk Ladang Lima serta jarang melihat unggahan Instagram Ladang Lima. Tahap ketiga adalah interest (ketertarikan), sebanyak 85,67\% responden yang memahami komunikasi pemasaran Ladang Lima menyatakan tertarik atau interest pada produk Ladang Lima, sedangkan sisanya sebanyak 14,33\% merasa tidak tertarik pada produk makanan sehat Ladang Lima karena sudah mengonsumsi makanan sehat sebelumnya. Tahap keempat yaiu intention (niat atau maksud untuk membeli), dari responden yang tertarik pada produk Ladang Lima, sebanyak $89,67 \%$ menyatakan memiliki niat untuk membeli produk Ladang Lima setelah melihat komunikasi pemasaran yang dilakukan melalui media sosial Instagram, sisanya sebanyak 10,33\% menyatakan tidak berniat membeli produk Ladang Lima karena sudah mengonsumsi makanan sehat merek lain dan telah percaya akan kualitas produk makanan sehat selain Ladang Lima. Tahap terakhir dalam Customer Response Index yaitu action (tindakan pembelian), sebanyak 69\% responden yang memiliki niat untuk 
Website : http://agritek.unmermadiun.ac.id/index.php/agritek

membeli produk Ladang Lima, benar-benar melakukan tindakan pembelian, sedangkan sisanya sebanyak $31 \%$ hanya memiliki niat untuk membeli namun tidak melakukan pembelian dengan alasan belum membutuhkan produk Ladang Lima.

Efektivitas komunikasi pemasaran menggunakan metode Customer Response index (CRI) ditentukan berdasarkan nilai CRI yang didapatkan melalui pengolahan presentase pada setiap tahap respon konsumen, suatu komunikasi pemasaran dikatakan efektif jika nilai akhir CRI (nilai CRI tahap action) lebih besar dari nilai CRI pada tahap unaware, no comprehend, no interest, no intention, dan no action (Durianto, 2003). Hasil pengolahan nilai akhir CRI atau nilai CRI pada tahap action yaitu 43,25\%, lebih besar dari nilai CRI pada tahap unaware sebesar 10,33\%, no comprehend sebesar 8,07\%, no interest sebesar $11,70 \%$, no intention sebesar 7,22\%, dan no action sebesar 19,43\%, sehingga dapat dikatakan bahwa komunikasi pemasaran yang telah dilakukan oleh PT ABA melalui media sosial untuk menumbuhkan kesadaran merek telah efektif, hal ini juga dibuktikan melalui analisis kesadaran merek (brand awareness), pada tingkat top of mind (puncak pikiran), merek makanan sehat yang pertama kali disebut oleh responden dengan jawaban terbanyak adalah merek Ladang Lima sebesar 56\%. Tingkat brand recall (pengingatan kembali suatu merek), merek yang disebutkan oleh responden setelah menyebutkan merek makanan sehat pertama adalah Lemonilo dengan presentase $42 \%$. Tingkat brand recognition (pengenalan merek), artinya responden telah mengetahui merek Ladang Lima tetapi tidak berada dalam ingatannya sehingga tidak disebutkan pada tingkat top of mind dan brand recall dengan presentase sebesar 6\%. Tingkat unaware of brand (tidak menyadari merek), terdapat $7 \%$ responden yang tidak mengetahui merek Ladang Lima di suatu pasar. Merek Ladang Lima menjadi puncak pikiran responden ketika ditanya mengenai makanan sehat, sehingga mendukung bahwa komunikasi pemasaran yang dilakukan telah efektif. Komunikasi yang dilakukan perusahaan telah mampu menumbuhkan kesadaran, pemahaman, ketertarikan, niat membeli, dan berakhir pada tindakan pembelian yang sesuai dengan tujuan perusahaan.

PT ABA kehilangan respon konsumen terbanyak di tahap intention menuju action pada hirarki CRI yaitu sebesar 20,67\%, artinya setelah melihat komunikasi pemasaran melalui Instagram Ladang Lima, banyak responden yang berniat untuk membeli produk Ladang Lima, tetapi tidak benar-benar melakukan tindakan pembelian. Perusahaan bisa memberikan stimulus untuk mendorong masyarakat melakukan tindakan pembelian dengan cara mengadakan promosi penjualan, seperti pemeberian diskon atau potongan harga, kuis berhadiah, maupun pemberian voucher. Perbaikan pada tahap respon konsumen akan meningkatkan nilai CRI, semakin tinggi nilai CRI akan berdampak signifikan pada penjualan, kontribusi pemasaran bersih, dan ROI pemasaran program iklan (kontribusi pemasaran bersih dibagi biaya dari program iklan) (Best, 2013).

\section{IV.KESIMPULAN}

Komunikasi pemasaran yang telah dilakukan oleh PT ABA telah efektif untuk menumbuhkan merek Ladang Lima, dilihat dari hasil pengolahan dengan metode Customer Response Index (CRI), nilai akhir CRI yaitu 43,25\%, lebih besar dari nilai CRI pada tahap unaware, no comprehend, no interest, no intention, dan no action, sehingga dapat dikatakan bahwa komunikasi pemasaran yang telah dilakukan oleh PT ABA melalui media sosial untuk menumbuhkan kesadaran merek telah efektif, hal ini juga dibuktikan dengan top of mind atau merek makanan sehat yang pertama kali disebut oleh responden dengan jawaban terbanyak adalah merek Ladang Lima sebesar 56\%. Perusahaan kehilangan respon konsumen terbanyak di tahap intention menuju action pada hirarki CRI yaitu sebesar 20,67\%, artinya responden hanya memiliki niat untuk membeli produk Ladang Lima tetapi tidak melakukan tindakan pembelian yang nyata. Nilai tersebut harus bisa ditingkatkan dengan cara menstimulus masyarakat melalui kegiatan bauran komunikasi pemasaran, salah satunya yaitu pemberian promosi untuk mendorong tindakan pembelian agar masyarakat tidak terhenti di tahap niat untuk membeli produk Ladang Lima.

\section{UCAPAN TERIMAKASIH}

Terimakasih kepada PT ABA yang telah memberi izin untuk melakukan penelitian ini, terimakasih kepada keluarga atas doa dan dukungannya serta terimakasih kepada berbagai pihak yang membantu kelancaran penelitian ini.

\section{DAFTAR PUSTAKA}

Andry, J. F., Prayogo, T., Wijaya, R. L., \& Kantona, Y. (2019). Effectiveness of Shopee Television Advertising Themed "Super Goyang Shopee" in Jakarta Society. Jurnal INFORM, 4(1).

Best, R. J. (2009). Market-based management: strategies for growing customer value and profitability. New Jersey: Prentice Hall.

BILLGiN, Y. (2018). The Effect of Social Media Marketing Activities on Brand Awareness, Brand Image and Brand Loyalty. Business \& Management Studies: An International Journal, 6(1), 128-148.

Durianto, D. (2003). Invasi Pasar dengan Iklan yang Efektif. Jakarta: Gramedia Pustaka Utama.

Ernestivita, G. (2016). Analisis Efektivitas Tagline Iklan Televisi Minuman Ringan Teh Botol Sosro Versi “Apapun Makanannya Minumnya Teh Botol Sosro" dengan Menggunakan Metode Customer Response Index (CRI). Jurnal Eksis, 11(2), 140-150.

Iblasi, W. N., Bader, D. M. K., \& Al-Qreini, S. A. (2016). The Impact of Social Media as a Marketing Tool on Purchasing Decisions (Case Study on SAMSUNG for Electrical Home Appliances). International Journal of Managerial Studies and Research, 4(1), 14-28.

Mihaela, O. O. E. (2015). The Influence of the Integrated Marketing Communication on the Consumer Buying Behaviour. Procedia Economics and Finance, $23,1446-1450$.

Mutiara, N. A., \& Hanifa, F. H. (2018). Efektivitas Iklan Pada Radio Play99Ers Bandung Dengan Metode Customer Response Index (CRI) (Studi Kasus Pada Iklan Babakaran Cafe Cabang Buah Batu Bandung). E-Proceeding of Applied Science, 4(2), 296-304.

Nastain, M. (2017). Branding dan Eksistensi Produk (Kajian Teoritik Konsep Branding dan Tantangan Eksistensi Produk). Channel, 5(1), 14-26.

Nawi, F. A. M., Tambi, A. M. A., Samat, M. F., \& Mustapha, W. M. W. (2020). a Review on the Internal Consistency of a Scale: the Empirical Example of the Influence of Human Capital Investment on Malcom Baldridge Quality Principles in Tvet Institutions. Asian People Journal, 3(1), 19-29. 
Website : http://agritek.unmermadiun.ac.id/index.php/agritek

Sarstedt, M., Bengart, P., Shaltoni, A. M., \& Lehmann, S. (2017). The Use of Sampling Methods in Advertising Research: A Gap Between Theory and Practice. International Journal of Advertising, 37(4).

Shahid, Z., Hussain, T., Park, N. C., Bagh, T., \& Scheme, H. (2017). The Impact of Brand Awareness on The consumers 'Purchase Intention. Journal of Marketing and Consumer Research, 33, 34-38.

Tarigan, R., \& Tritama, H. B. (2016). The Effect of Social Media to the Brand Awareness of A Product of A Company. CommIT (Communication and Information Technology) Journal, 10(1).

Ursachi, G., Horodnic, I. A., \& Zait, A. (2015). How Reliable are Measurement Scales? External Factors with Indirect Influence on Reliability Estimators Procedia Economics and Finance, 20(15), 679-686.

We Are Social \& Hootsuite. (2020). Indonesia Digital report 2020. Global Digital Insights. 247.

Yusup, F. (2018). Uji Validitas dan Reliabilitas Instrumen Penelitian Kuantitatif. Jurnal Tarbiyah Jurnal Ilmiah Kependidikan, 7(1), 17-23. 